\title{
Label Claims Influences on Acceptance: Consumers' Changes Expectation and Intention in a Case Study with Functional Chocolate Ice Cream
}

\author{
Palazzo A. B. (Corresponding author) \\ Department of Food and Nutrition \\ School of Food Engineering / University of Campinas - UNICAMP - Campinas / Brazil \\ Postal address: 80 Monteiro Lobato st, 6121, Zip code 13083-862, Campinas, SP, Brazil.
}

Tel: 55-19-3521-4084Ｅ-mail: alessandrabpalazzo@gmail.com

Bolini H. M. A.

Department of Food and Nutrition

School of Food Engineering / University of Campinas - UNICAMP - Campinas / Brazil Postal address: 80 Monteiro Lobato st, 6121, Zip code 13083-862, Campinas, SP, Brazil. Tel: 55-19-3521-4083Ｅ-mail: hellini@unicamp.br

Received: September 25, 2017 Accepted: October 28, 2017 Published: October 31, 2017 doi:10.5296/jfs.v6i1.11912

URL: https://doi.org/10.5296/jfs.v6i1.11912

\begin{abstract}
Label claims leads to consumer driven toward food purchase intention and acceptance. The aim of this study is provide information about label influences using a diet chocolate ice cream. The ice cream was sweetened with polydextrose, maltitol and neosucralose. A group of 112 consumers expressed their perception under two conditions: blind (only testing samples) and informed (evaluating samples with label claim), using two scales: a 9-cm unstructured hedonic scale and a 5-point purchase intention questionnaire. An analysis of variance, Tukey's test and PCA were calculated. Considering overall liking, consumers differed significantly the samples $(\mathrm{P} \leq 0.05)$ and claims containing "Fiber" were more
\end{abstract}




\section{MInstitute Macrothink $_{\text {Int }}$}

accepted. Furthermore, the purchase intention was higher under the informed condition, mainly affected by claim with "Fiber", and so by term "Zero". These findings showed that changes in the functional property claim influenced consumers' acceptance. In general, they preferred healthy information, like "With Fiber" and dislike terms associated "Diet" words.

Keywords: Diet ice cream, Sweeteners, Claims, Functional, Consumer

\section{Introduction}

According to the Food and Drugs Administration - FDA (2016), health claims describe a relationship between a food substance (a food, food component, or dietary supplement ingredient), and reduced risk of a disease, such as cardiovascular problems or health-related condition.

Torres-Moreno et al. (2012) evaluated six dark chocolates scoring the consumer liking in relation to three conditions (blind, expected and informed). Their results showed that consumer hedonic scores were mainly affected by the brand under expected condition. In the blind condition, differences in liking scores were motivated by to the type of product: samples with a high percentage of cocoa were less preferred by consumers.

Schouteten et al. (2017) investigated the brand information impact on children's overall liking of biscuits. They realized that brand influenced the informed liking scores. Some efforts have been realized to understand the consumers' perception of nutrition and health claims. A study with French consumers' perceptions using both qualitative and quantitative methods resulted in conclusions like: some types of claims are deemed more accepted and credible than others (Masson et al., 2016).

Some efforts between the food industry and the academic field have improved studies using ice cream replacements (Aykan et al., 2008) or sucrose substitution with some sweetenetrs such as sucralose, aspartame, neotame, thaumatin and saccharin (Palazzo \& Bolini 2017; Cadena \& Bolini, 2011; Ozdemir et al., 2015).

Sucrose replacement in ice cream was studied, using different high sweeteners and bulking agents. A study conduced by Maia et al. (2008) reported consumer preference (ice cream flavored with: vanilla, strawberry and chocolate) sweetened both with sucrose and xylitol. The ice creams sweetened with sucrose were preferred when compared to those sweetened with xylitol. Furthermore, the chocolate sample showed the lowest sensory difference, followed by strawberry and vanilla ice creams.

The demand for alternative sweeteners which do not interfere in relation to consumers preference has prompt researchers to new discoveries, like de use of Neosucralose by food industry. This high intensity sweetener is a blend composed by acessulfame- $\mathrm{K}$, sucralose and neotame, usually used associated to diet and light products, such as reported by some studies (Palazzo and Bolini, 2017; Paixão et al., 2014). They reported the successful replacement of sucrose, using neosucralose in ice cream and chocolate milk beverage.

This study was designed to verify the consumer expectation and acceptability of diet chocolate ice cream, sweetened with a new kind of high sweetener, neosucralose, using six different label claims to identify how their interesting level and overall liking were affected. 


\section{Ml Macrothink}

\section{Material and Methods}

\subsection{Sample Product}

The ice cream was produced with a sweetener blend Neosucralose [(100:50:1) (acesulfame-K: sucralose:neotame), SweetMix, Brazil)] and was prepared using: 16.5\% fat powered milk (Consulat), $61.5 \%$ water, $2.8 \%$ cocoa power, $4.5 \%$ vegetal fat and $0.7 \%$ stabilizer/emulsifier. Polydextrose and Maltitol (Tovani Benzaquen, Brazil) were used as bulking agents. The equi-sweeteness was previously determined according to (Palazzo \& Bolini, 2017).

Dry materials were dispersed under agitation into the liquid ingredients using a mechanical mixer (Siemsen Ltda, Brazil). Then, the emulsifier/stabilizer was added and the liquid was mixed in a Cuisinart Frozen Yogurt-Ice Cream mixer during 15 minutes. The ice cream was frozen at $-10 \mathrm{C}$ and remained at constant temperature using a batch freezer (Consul Freezer 530, Brazil).

\subsection{Functional and Diet/Light Claims}

The six label claims used in the study are shown in Figure 1. Pictures containing claims were presented to consumers in the same way as each sample. Functional and diet statements were combined to create six ice cream claim concepts, according to Table 1.

Table 1. Selected diet/health/functional claims

\begin{tabular}{ll}
\hline Samples & Claims \\
\hline 1 & Diet chocolate ice cream \\
2 & Diet chocolate ice cream - with no sugar \\
3 & Zero Sugar chocolate ice cream - with no sugar \\
4 & Light chocolate ice cream \\
5 & Chocolate ice cream with fiber \\
6 & Chocolate ice cream - with fiber. "Polydextrose - fiber that assists intestine \\
& function. Its consumption must be associated with a balanced diet and healthy \\
& life habits" \\
\hline
\end{tabular}

Table 2. Interesting level of diet chocolate ice cream consumers $(n=112)$

\begin{tabular}{lllllll}
\hline Ice cream claims & $\mathrm{A} 1$ & $\mathrm{~A} 2$ & $\mathrm{~A} 3$ & $\mathrm{~A} 4$ & $\mathrm{~A} 5$ & $\mathrm{~A} 6$ \\
\cline { 2 - 6 } Blind condition (b) $^{1,2}$ & $5.39^{\mathrm{a}}$ & $5.43^{\mathrm{a}}$ & $5.52^{\mathrm{a}}$ & $5.52^{\mathrm{a}}$ & $5.61^{\mathrm{a}}$ & $5.61^{\mathrm{a}}$ \\
Informed condition (i) $^{\text {a }}$ & $4.50^{\mathrm{b}}$ & $4.55^{\mathrm{b}}$ & $4.55^{\mathrm{b}}$ & $4.98^{\mathrm{b}}$ & $5.25^{\mathrm{a}}$ & $5.55^{\mathrm{a}}$ \\
\hline Overall liking $^{3}$ & $4.96^{\mathrm{c}}$ & $5.30^{\mathrm{bc}}$ & $5.45^{\mathrm{bc}}$ & $5.48^{\mathrm{bc}}$ & $5.87^{\mathrm{ab}}$ & $6.14^{\mathrm{a}}$ \\
\hline${ }^{1} 7$ point scale (1= lower interesting; 7= higher interesting) & & & \\
${ }^{2}$ Means with a same superscript letter are not significantly different (p>0.05) \\
${ }^{3}$ 9 point scale (1= dislike extremely; 9= like extremely) and means with a same superscript \\
letter are not significantly different (p>0.05) on row associated with overall liking
\end{tabular}




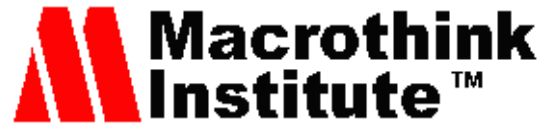
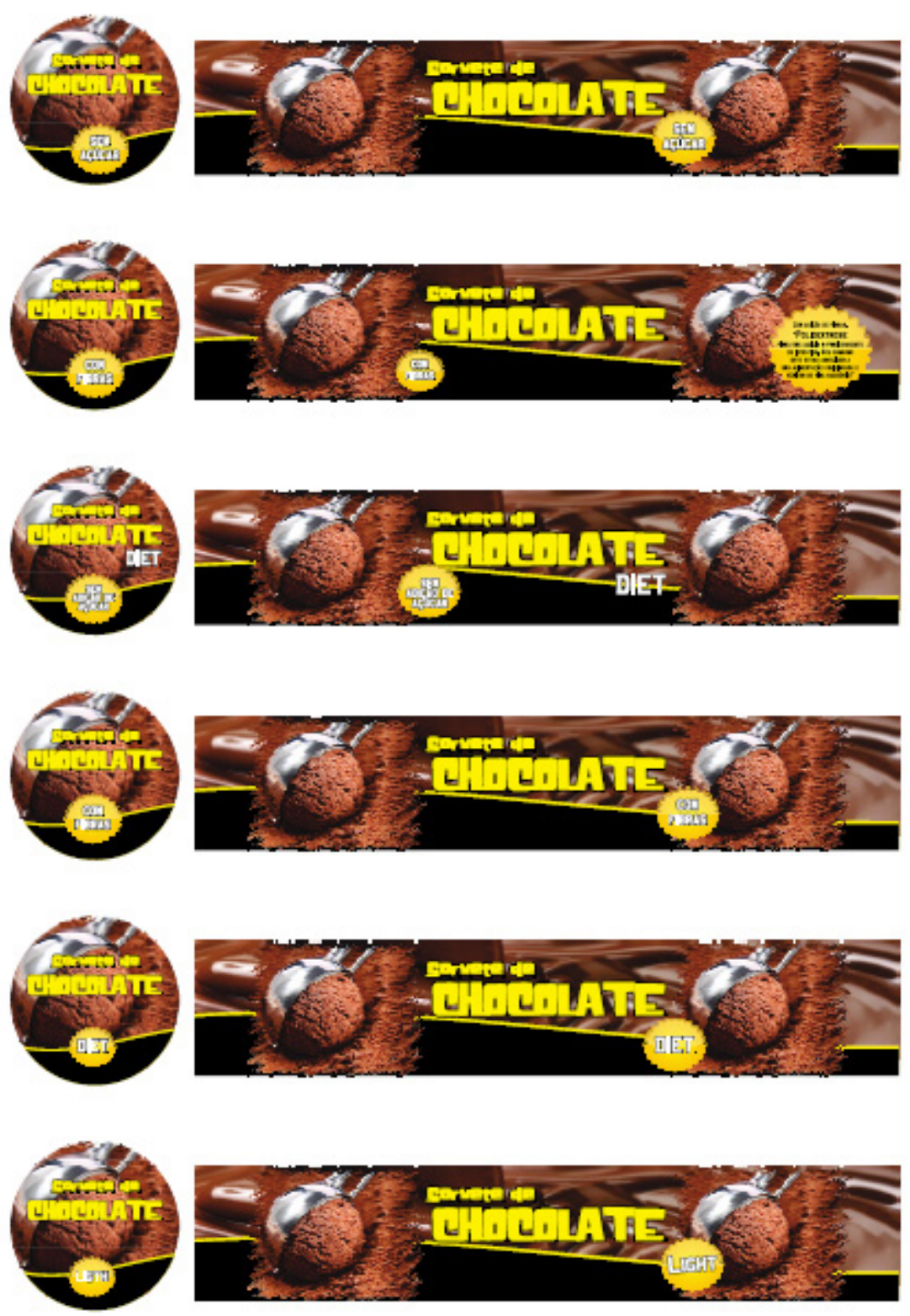

Figure 1. Labels of functional chocolate ice cream, designed with six different terms: (1) diet, (2) diet with no sugar, (3) zero sugar, (4) light, (5) with fiber and (6) with fiber "Polydextrose"

The label claim " 6 " provide a health statement, with an expression about a relationship between a food substance (Polydextrose) and a health-related condition (intestine function).

The label information does directly assists consumers who are seeking nutrition knowledge and leads to better discrimination toward the different food alternatives.

\subsection{Design of the Study}

Samples coded with 3-coded digit numbers were presented to tasters in disposable plastic cups with $15 \mathrm{~g}$ of diet chocolate ice cream followed by the figure with the property claim coded with the same 3-digit numbers. 


\section{Macrothink}

Tests were carried out in individual air-conditioned booths $\left(22^{\circ} \mathrm{C}\right)$ in the Sensory Analysis Laboratory/School of Food Engineering (FEA/Unicamp) and evaluated under white light, thus ensuring comfort and privacy for the panelists. A complete balanced block was used (MACFIE et al., 1989) and the samples were presented sequentially in a monadic way.

The consumer group $(\mathrm{n}=112)$ was composed by graduation and undergraduation students at the University of Campinas and was between 18 and 56 years of age and $62 \%$ being women. The selection criterion was that subjects had to be regular consumers of dairy ice cream.

Consumers evaluated the diet chocolate ice creams, under blind and informed conditions, in toward interesting level $(1=$ lower interesting level; $7=$ higher interesting level $)$, under blind and informed conditions. A purchase intention evaluation was made using a 5-point scale ranging from 1 = definitively would not buy; 5 = definitively would buy.

Finally, an affective test, through informed condition together diet ice cream sample, was determined using a 9-cm unstructured line hedonic scale (Stone \& Sidel, 2004; Stone et al., 2012), with anchors of "dislike extremely" on the left and "like extremely" on the right.

The data were collected using Fizz Sensory Network Model H 2:40 (Biosystemes, Couternon, France 2009).

\subsection{Data Analyses}

An analysis of variance (ANOVA) was performed on the consumers' overall liking scores, and mean ratings were calculated using Tukey's test $(\mathrm{p}=5 \%)$. Statistical calculations were generated by the Statistical Analysis System - SAS (2017) program. Principal Component Analysis (PCA) technique was employed to examine the sensory overall liking of six claims using XLSTAT (Xlstat, New York, NY, USA). From purchase intention evaluation, the percentage of consumers rating the samples in each one of the five points of the scale was obtained $(1=$ definitively would not buy; 2 = probably would not buy; $3=$ might buy; $4=$ probably would buy and $5=$ definitively would buy).

\section{Results}

\subsection{Interesting Level of Label Claims}

The interesting level results of the diet chocolate ice creams analysis are present on Table 2.

Under blind condition, there was no difference among samples, as expected because all ice creams were the same product (A1b to A6b).

Consumers evaluated the samples under informed condition and so, reported that the two claims containing the term "Fiber" were similar and most accepted (A5i and A6i).

It's an interesting point of the study, because even all the "Ai" samples being the same, consumers evaluated them as different, accepting the product with a high liking score when the term "Fiber" was associated. This fact only happened under informed condition, when consumers analyzed both, ice cream and label claim.

In addition, only those two claims keep the same interesting level degree before and after the claim presentation.

There was a drop in the interesting level in relation of the samples numbered A1 to A4, representing by subscript letters "a" and "b", analyzed with $5 \%$ of significance level. The results showed the influence of the claim terms contained in the label towards the consumer's 


\section{Macrothink}

expectation (Figure 2).

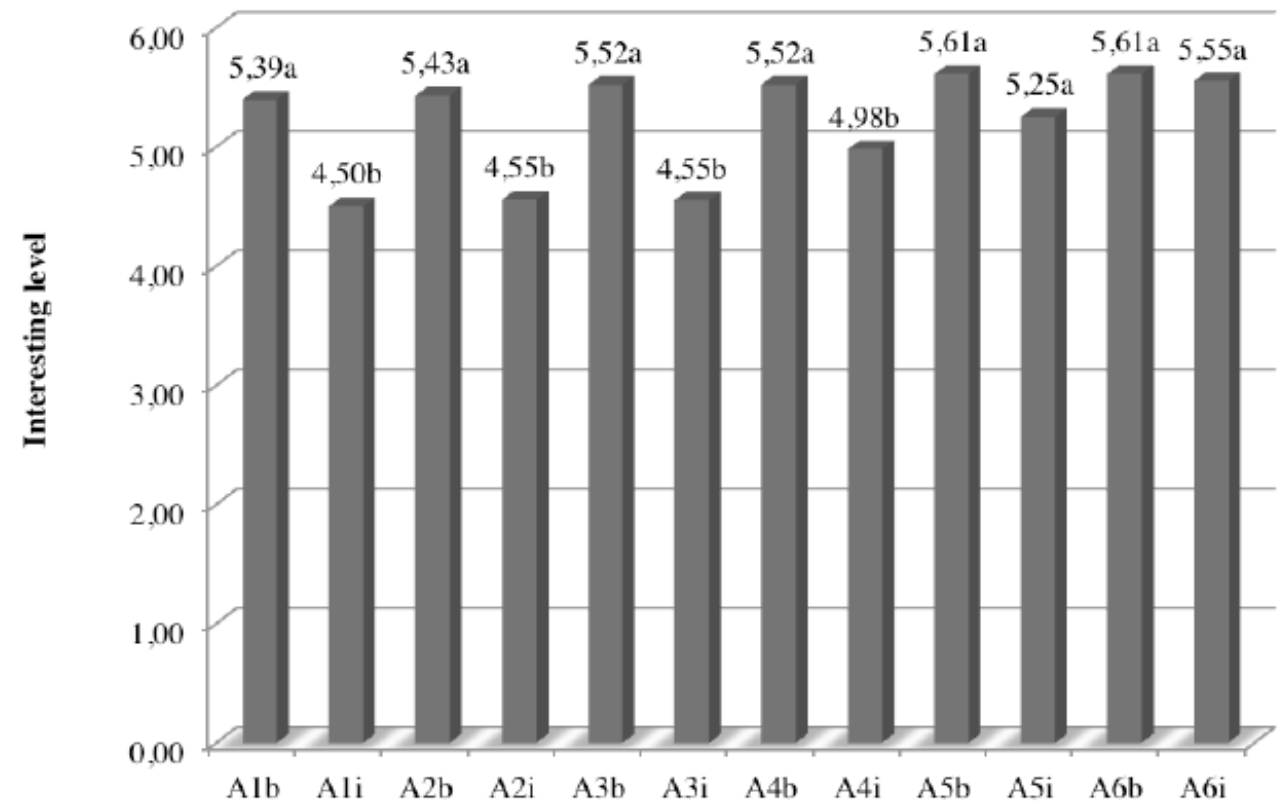

Figure 2. Consumers interesting level under blind (b) and informed (i) conditions ( 7 point scale $(1=$ lower interesting; $7=$ higher interesting; Means with a same superscript letter are not significantly different $(\mathrm{p}>0.05))$

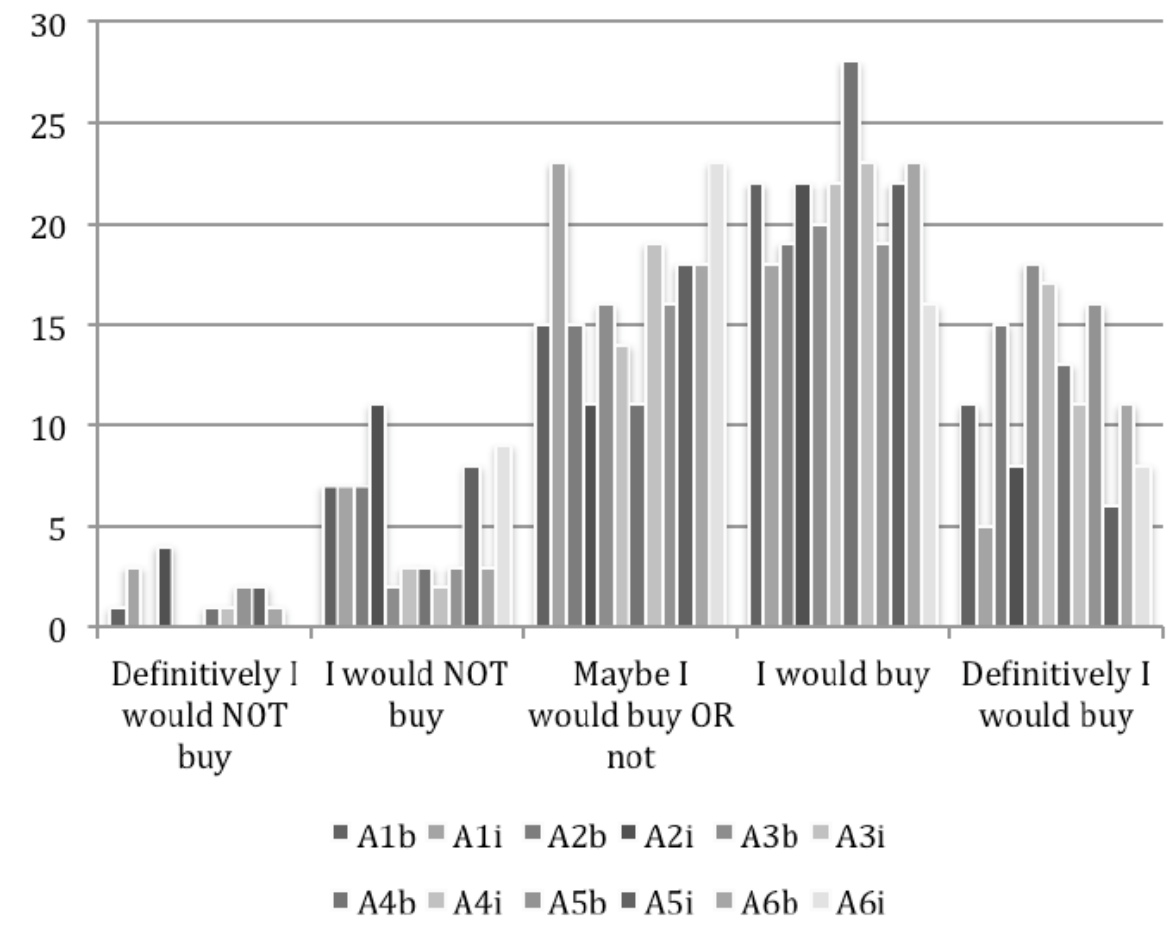

Figure 3. Purchase intention under blind (b) and informed (i) conditions 


\section{MInstitute ${ }^{\text {Mink }}$}

Considering the 7-point scale, all the results were reasonable evaluated, representing a high interesting level by ice cream' consumers (all values above 4,50).

\subsection{Consumers' Intention before and after Informed Condition}

In regards to the chocolate ice cream purchase intention (Figure 3), consumers answered that they "definitely would buy" the product with the claim containing "Zero" term. The sentences numbered 3 and 5 were better evaluated, presenting "Zero" and "Fiber" statements, respectively.

It's important to note that samples 2, 3 and 5 showed higher purchase intention after consumers tested the products (considering the answer "I would buy this product"). The increase values (blind to informed answer) were 5\%,4\% and 5\% for sample with label claim 2,3 and 5 , respectively.

The low purchase intention was associated with the term "Diet", represented with the samples 1 and 2, evaluated by consumers as "Definitely we would not buy". People may associated the term "Diet" with some product with medical or therapeutic functions, while terms regarding healthy conditions, as "Fiber", "Zero calories" or "Zero sugar", could bring positive attitudes.

As reported by Barrios et al. (2008), it's important to study the influence of attitudes, beliefs and opinions on food choice and purchase intention, mainly in functional food, getting an alternative type of product. Claims are designed to provide useful information to the consumer concerning the benefits of food, associating the current law (Nocella and Keneddy, 2012). Furthermore, understanding the consumer's knowledge about the food claims is a very tool to get a great acceptance of certain product.

\subsection{Consumers' Overall Liking}

Considering the overall liking, consumers differed significantly the samples with the term "Fiber" from the other label claims $(\mathrm{P} \leq 0.05)$. These results showed an impact on consumers' acceptance, influenced by functional claims.

In view of the consumer's assessment of the six labeling options presented, there was a significantly higher acceptance of the claims with more information.

The samples contained the word claims "Chocolate Ice Cream - with fiber" and "Chocolate Ice Cream - with fiber - Polydextrose - fiber that assists intestine function. Its consumption must be associated with a balanced diet and healthy life habits" were significantly more accepted than samples containing other statements.

According to Masson et al. (2016), the structure-function-type claims, associating a nutrient' molecular to its metabolic function, showed deemed more credibility from consumers.

A PCA (Figure 4) showed that the first two principal components described $72 \%$ of total variation in the sensory data. The first two factors allowed to represent: PC $159 \%$ of variation among samples whereas PC2 described 13\% of variation. When 2 samples were far from the center and close to each other, they are significantly positively correlated. So, the sample claim numbered 3 (Zero) showed low correlation with the others. 
F1 and F2: $71,98 \%$

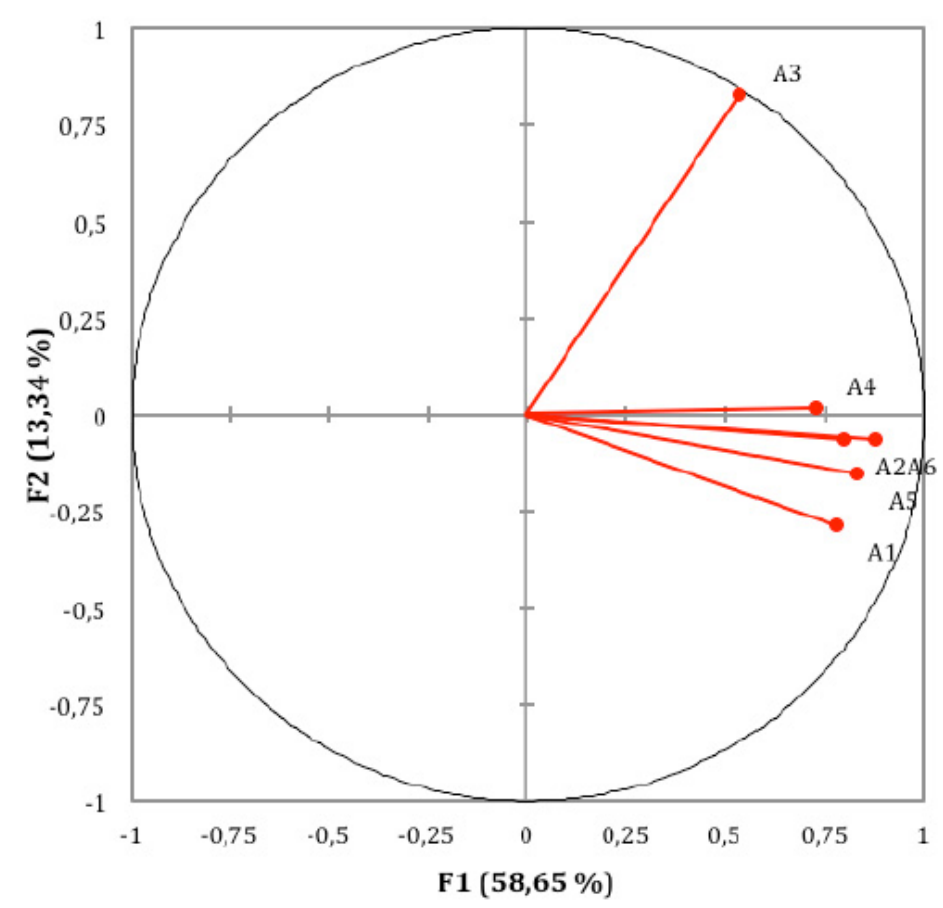

Figure 4. PCA of diet chocolate ice cream claims under informed conditions

These findings show that the changes in the functional property claim influenced the consumers' acceptance. In general, consumers preferred the sample with some health or functional (as product contains any functional property) information.

Health claims, whether made directly on products or through secondary sources, for example the media, are key to markets for functional foods and nutraceuticals, especially where the ingredient is novel and the related health effects are not well known (Hailu et al., 2009).

Oliveira et al. (2016) studied how the claims influenced consumers in relation of their position on label food product. They observed that consumers' attention to specific areas of interest labels decreased as information density increased, suggesting that health claims should be written as concise as possible to assure that consumers fully process them.

\section{Conclusions}

The present work is consistent with other study using health claims in different products, confirming that consumers expect health and functional claims to be on healthier foods. The conscience about food intake and functional property became more common nowadays. Label claims leads to consumer driven toward food purchase intention and acceptance.

Consumers showed their perception in relation to accepted products that carried out functional informational, improving the food industries to develop better and better food and beverages around the world. So, future research would enhance this field of product development, searching for consumer answers and expectative about many available foods.

\section{References}

Aykan, V., Sezgin, E., \& Guzel-Seydim, Z. B. (2008). Use of fat replacers in the production 
of reduced-calorie vanilla ice cream. Eur. J. Lipid Sci. Technol., 110, 516-520. https://doi.org/10.1002/ejlt.200700277

Barrios, E. X., Bayarri, S., Carbonell, I., Izquierdo, L., \& Costell, E. (2008). Consumer attitudes and opinions toward functional foods: a focus group study. J Sens Stu, 23(4), 514-525. https://doi.org/10.1111/j.1745-459X.2008.00169.x

BIOSYSTEMES. (2009). Software solutions for sensory analysis and consumer tests. Fizz Sensory Software version $2.40 \mathrm{H}$. Couternon, France.

Cadena, R. S., \& Bolini, H. M. A. (2011). Time-intensity analysis and acceptance test for traditional and light vanilla ice cream. Food Res Int, 44, 677-83. https://doi.org/10.1016/j.foodres.2010.12.012

Cadena, R. S., Cruz, A. G., Netto, R. R., Castro, W. F., Faria, J. A. F., \& Bolini, H. M. A. (2013). Sensory profile and physicochemical characteristics of mango nectar sweetened with high intensity sweeteners throughout storage time. Food Res Int, 54(2), 1670-9. https://doi.org/10.1016/j.foodres.2013.10.012

FDA. Food and Drug Administration. (2016). Label Claims for Conventional Foods and Dietary Supplements. Silver Spring, MD. Assessed on Jan 31th 2017.<http://www.fda.gov/Food/IngredientsPackagingLabeling/LabelingNutrition/ucm11144 7.htm>

Hailu, G., Boecker, A., Henson, S., \& Cranfield, J. (2009). Consumer valuation of functional foods and nutraceuticals in Canada. A conjoint study using probiotics. Appetite, 52, 257-265. https://doi.org/10.1016/j.appet.2008.10.002

Macfie, H. J., Bratchell, N., Greenhoff, K., \& Vallis, L. V. (1989). Designs to balance the effect of order of presentation and first-order carry-over effect in halls tests. J Sens Stud, 4(2), 129-148. https://doi.org/10.1111/j.1745-459X.1989.tb00463.x

Maia, M. C. A., Galvão, A. P. G. L. K., Modesta, R. C. D., \& Júnior, N. P. (2008). Consumer evaluation of ice cream with xylitol. J Food Sci Technol, 28(2), 341-47.

Nocella, G., \& Kennedy, O. (2012). Food health claims - What consumers understand. Food Policy, 37, 571-580. https://doi.org/10.1016/j.foodpol.2012.06.001

Oliveira, D., Machín, L., Deliza, R., Rosenthal, A., Walter, E. H., Giménez, A., \& Ares, G. (2016). Consumers' attention to functional food labels: Insights from eyetracking and change detection in a case study with probiotic milk. LWT Food Science Technol, 68, 160-167. https://doi.org/10.1016/j.lwt.2015.11.066

Ozdemir, C., Arslaner, A., \& Ozdemir, S. (2015). The production of ice cream using stevia as a sweetener. J Food Sci Technol, 52(11), 7545-48. https://doi.org/10.1007/s13197-015-1784-5

Masson, E., Debucquet, G., Fischler, C., \& Merdji, M. (2016). French consumers' perceptions of nutrition and health claims: A pshychosocial-anthropological approach. Appetite, 105, 61-629. https://doi.org/10.1016/j.appet.2016.06.026

Paixão, J. A., Rodrigues, J. B., Esmerino, E. A., Cruz, A. G., \& Bolini, H. M. A. (2014). Influence of temperature and fat content on ideal sucrose concentration, sweetening power, and sweetness equivalence of different sweeteners in chocolate milk beverage. Journal of dairy science, 97(12), 7344-7353. https://doi.org/10.3168/jds.2014-7995 


\section{Macrothink}

Palazzo, A. B., \& Bolini, H. M. A. (2017). Sweeteners in Diet Chocolate Ice Cream: Penalty Analysis and Acceptance Evaluation. Journal of Food Studies, 6(1), 1. https://doi.org/10.5296/jfs.v6i1.10655

SAS System for Windows (Statistical Analysis System). (2017). Version 9.4 Service Pack 3. SAS Institute Inc. 2002-2003. Carry. NC. USA.

Schouteten, J. J., Steur, H. D., Lagast, S., Pelsmaeker, S. D., \& Gellynck, X. (2017). Emotional and sensory profiling by children and teenagers: A case study of the check-all-that-apply method on biscuits. $J$ Sensory Stud, 32(1), 1-11. https://doi.org/10.1111/joss.12249

Torres-moreno, M., Tarrega, A., Torrescasana, E., \& Blanch, C. (2012). Influence of label information on dark chocolate acceptability. Appetite, 58(2), 665-671.

Stone, H., Bleibaum, R., \& Thomas, H. A. (2012). Sensory evaluation practices. Academic press.

Stone, H., \& Sidel, J. L. (2004). Sensory evaluation practices. (3rd. ed). New York: Academic Press. https://doi.org/10.1016/B978-012672690-9/50008-1

\section{Copyright Disclaimer}

Copyright for this article is retained by the author(s), with first publication rights granted to the journal.

This is an open-access article distributed under the terms and conditions of the Creative Commons Attribution license (http://creativecommons.org/licenses/by/3.0/). 